\title{
AC 2007-2175: IMPROVING UNDERGRADUATE ENGINEERING DESIGN INSTRUCTION THROUGH LESSONS LEARNED MENTORING FIRST LEGO LEAGUE
}

\section{Douglas Gabauer, Virginia Tech}

Douglas J. Gabauer is a Graduate Research Engineer in the Center for Injury Biomechanics at Virginia Tech. He received his B.S. in Civil Engineering (2001) and M.S. in Mechanical Engineering (2003) from Rowan University. His research has been published both in national and international venues on subjects including roadside safety, injury criteria, event data recorders, and vehicle crashworthiness. He is also a recipient of the 2006 Dwight D. Eisenhower Transportation Fellowship.

Tim Bayse, Virginia Tech

Tim Bayse is a graduate student in Civil Engineering at Virginia Tech.

\section{Janis Terpenny, Virginia Tech}

Janis Terpenny is an Associate Professor in the Department of Engineering Education with affiliated positions in Mechanical Engineering and Industrial \& Systems Engineering at Virginia Tech. She is co-Director of the NSF multi-university Center for e-Design. Her research interests focus on methods and representation schemes to support early design stages of engineered products and systems. She is currently a member of ASEE, ASME, IIE, and Alpha Pi Mu. She is the Design Economics area editor for The Engineering Economist journal.

\section{Richard Goff, Virginia Tech}

Richard M. Goff is the Pete White Chair for Innovation in Engineering Education, Associate Professor, and Assistant Head of the Department of Engineering Education at Virginia Tech. An award winning teacher, his main areas of research and teaching are design and design education. 


\title{
Improving Engineering Design Instruction through Lessons Learned from FIRST Lego League Mentoring
}

\begin{abstract}
Engineering design courses at the undergraduate level pose substantial challenges to novice as well as veteran faculty, especially when implementing open-ended design problems to facilitate student learning. This paper presents a novel perspective on strategies and techniques used to teach undergraduate engineering design based on experience gained from mentoring FIRST Lego League (FLL) teams. FLL is designed to provide children age 9 to 14 with practical, hands-on experience in basic engineering design and computer programming. With guidance from mentors and coaches, teams are tasked with designing, building, and programming Lego ${ }^{\circledR}$ Mindstorms ${ }^{\mathrm{TM}}$ robots to perform specific objectives. Judging is based on the performance of the robot, a team presentation, teamwork, and a team discussion regarding the robot design.

This paper describes FLL mentoring experience, and paradigms employed by FLL, in the context of teaching engineering design at the undergraduate level. Parallels are drawn between the FLL mentoring experiences and similar problems encountered in project-based undergraduate design courses. Improved teaching and evaluation paradigms are presented with the intent of enhancing the undergraduate design experience. FLL mentoring experience will be presented at two distinct team levels; one at the elementary school and one at the middle school level. Experiences at both levels are discussed with respect to their relevance to undergraduate engineering design and associated strategies that facilitate their implementation.
\end{abstract}

\section{Introduction}

Lego ${ }^{\circledR}$ Mindstorms ${ }^{\mathrm{TM}}$ hands-on design, construction and programming have been incorporated into engineering courses at several Universities. The United State Air Force Academy developed a race car competition based on the Lego ${ }^{\circledR}$ Mindstorms ${ }^{\mathrm{TM}}$ platform to aid cadets with fundamental rigid body dynamics concepts ${ }^{1}$. Lego ${ }^{\circledR}$ Mindstorms $^{\mathrm{TM}}$ at Virginia Tech are used to facilitate an interdisciplinary freshman design course that couples mechanical engineering and industrial design students ${ }^{2}$. At Tufts University, the mechanical engineering department incorporated Lego $^{\circledR}$ Mindstorms ${ }^{\mathrm{TM}}$ into freshman and senior level courses ${ }^{3}$. The National University of Ireland employs the Lego ${ }^{\circledR}$ Mindstorms ${ }^{\mathrm{TM}}$ platform in an introductory engineering design course ${ }^{4}$. Other universities that have developed hands-on engineering courses or design modules using Lego products include University of Wyoming ${ }^{5}$ and Southern Illinois University - Edwardsville ${ }^{6}$.

In addition to use at the university level, Lego ${ }^{\circledR}$ Mindstorms $^{\mathrm{TM}}$, in the form of the FIRST Lego League $^{7}$ (FLL) competition, are also used at the elementary and middle school levels across the country and internationally to promote interest in science and engineering in the young. Previous researchers have outlined instructional modules for mentoring teams involved in the FLL competition ${ }^{8}$ and reported on students' experience with mentoring an FLL team ${ }^{9}$. Through the mentoring experiences of the graduate student authors, the purpose of this paper is to 
examine the usefulness FLL team mentoring experience, especially to how it relates to teaching undergraduate engineering design.

\section{FIRST Lego League Background}

1989 saw the creation of the FIRST ${ }^{10}$ as a method to make science and technology fun for kids of all ages. FIRST (For Inspiration and Recognition of Science and Technology) is a multinational non-profit organization that has undertaken this task. Their main mission statement is an aspiration to transform culture by making science, math, engineering, and technology as cool for kids as sports are today. Founder Dean Kamen, inventor of the Segway Human Transporter envisioned team robotic competitions for high school students would have sponsorship and assistance from local companies, teachers, coaches and other volunteers could design, build and test robots in a fun competitive environment. The cornerstone of FIRST's success, and these authors introduction, has been the work of its thousands of volunteers. Across the United States volunteers, mentors, professional engineers, teachers and others work with students to help guide their creative spirit in creating robots to overcome predefined challenges. This idea has branched into many different competitions including the FIRST Robotics Competition (A multinational venture), FIRST Lego League (ages 9-14), FIRST VEX Challenge (high school students) and FIRST Place (working laboratories for all ages). The following paragraph will summarize the intent, purpose and history of FIRST Lego League (FLL).

\section{What is FIRST Lego League?}

Seen as the "little league" of the FIRST Robotics Competition, the FLL is the result of a growing partnership between FIRST and the Lego Group. As the goal of FIRST is to inspire young minds to the exciting fields of engineering, science, math and technology, FLL also extends this ideal to children ages 9 through 14 in hopes of inspiring a celebration of the sciences. Seen as a hands-on, interactive robotics program with a sports-like atmosphere, teams of up to 10 players focus on such things as team building, problem solving, creativity and analytical thinking. Each year a new challenge is unveiled and over an approximate 8 week period teams will strategize, design, build, program, test and refine a fully autonomous robot capable of completing the various missions as defined by FLL using LEGO ${ }^{11}$ Robotics technology. Unlimited resources are available to the students including the web, teachers, coaches, volunteering adults and engineers. These fun activities are a great method of meeting students where they are and helping creative a positive image of science and technology. The 2006 FLL challenge was the Nano Quest Challenge for which an overview is provided below:

\section{Overview of the Nano Quest Challenge}

The theme of Nanotechnology was chosen since it is a new scientific frontier that will impact many facets of society today. With applications in medicine, computers and the environment the nano world, which is 100,000 times smaller than the thickness of a single strand of hair, provides a scientific display of a dynamic environment that constantly moves and vibrates. Now as an introduction to nanotechnology, students will be able to move atoms and molecules make amazing discoveries, help cure diseases and travel through the human body using the LEGO robotic technology to overcome obstacles and challenges along the way. 


\section{Learning from FLL}

Based on our experience as FLL mentors, the following is a list of lessons learned and their relevance to teaching design at the undergraduate level:

\section{Importance of Communication}

This lesson is perhaps the most obvious when mentoring at the elementary level. One of the authors experienced this first-hand as he attempted to explain his dissertation topic to the unsuspecting Lego Leaguers in a mild collegiate level dialect, as he would to any adult inquiring about such information. To his surprise, there was a sea of perplexing looks for roughly ten seconds followed by complete inattention. What had he done incorrectly? The epiphany was immediate; it was possible that the words were understandable to the audience, but the author failed to sufficiently relate it to what the children already knew.

From the undergraduate engineering design perspective, this is both obvious and relevant. Speak to the students in a language to which they can relate and understand. Eye contact between instructor and students is of utmost importance and provides vital information regarding student interest and content understanding. Failure to make a conscious effort to maintain this contact can be detrimental, especially in the context of a lecture. Do not take for granted what the students can do or should already know.

\section{Success as a Motivator}

Even the smallest of successes can be an enormous motivator. At the outset, the FLL team mentored by Author 1 appeared overwhelmed by the number and scope of the robot missions. Originally, the idea was to have small sub-teams work on constructing attachments and programming for different missions; progress remained slow and ideas for attachments tended to be duplicated by other sub-teams. Consolidating the efforts of the sub-teams to focus on one single mission, the pizza molecule mission, led to the first successful completion of a mission by the team. Not a particularly difficult mission, but this small success energized the team and created an atmosphere of excitement for the completion of the remainder of the missions.

With difficult design problems it is easy for students to get discouraged. It helps to start with a small but related component of the design that will lead to quick and early success. The idea is that quick and early success builds confidence in the student and/or team's abilities and instills motivation. Nothing is worse than working on a project that you are not interested in or lack the motivation to complete. Success also helps to bind the team together (working towards a common goal, team pride, etc.).

\section{Guiding vs. Spoon Feeding}

There is a very fine line between mentoring/guiding and spoon feeding. Students in the FLL have not had fundamental courses such as physics, statics, and dynamics and often tend to lack basic understanding of fundamental mechanical and physical concepts. It was a very difficult 
task to NOT just tell the students what would work and what wouldn't work. Concepts that escaped the students or were baffling to them were often seen by the authors as common knowledge. The challenge was to recognize the concepts that they did not grasp and provide them a guide toward coming to their own conclusions.

Again, although it may be an obvious observation, the guiding vs. spoon feeding balance is directly applicable to teaching design at the undergraduate level. In this case, however, the students will have a well developed background in the physical sciences but may lack connectivity between fundamental concepts. Communication is critical in this instance too; the instructor must recognize the gaps in knowledge or concept integration and lead the student toward understanding. As evident in the mentoring experiences of both graduate student authors, spoon feeding information was much less invigorating than involving the students in the process of discovery. The difficulty came in practicing this as both authors noted that it required thought to guide rather than just inform. Effective strategies employed were to let the students experiment, providing guidance only when needed, as well as asking the students to explain how or why a particular design works (or doesn't work). These are applicable to the undergraduate design as well - the trick is to find new and innovative ways to awaken the inner curiosity of the students. For at least one of the graduate student authors, whose goal is a career in academia, this take home message was an invaluable one.

\section{Dealing with the Uninterested}

One particular student on author 1's team was almost entirely not interested in participating in FLL. This was very frustrating to the teacher as well as the mentor. Both teacher and mentor often asked themselves, "Why did they even bother to show up?" This posed a formidable challenge; both to get the student involved and prevent the student from distracting the other students. Discovering ways to engage such a student is a worthy challenge for the teacher and mentor. If you can discover something about the project that peaks their interest and then build on that, it can become an effective engagement strategy. In this particular case, the teacher was able to effectively channel the energy of the "uninterested" student towards the team presentation component of the FLL.

The prevalence of complete loss of interest in the undergraduate engineering design environment is likely less than that found in the FLL environment; however, keeping the interest of the students remains of paramount importance. Based on the early exposure to this issue through FLL mentoring, one author feels much more capable of handling it in the future. Both graduate authors now recognize that keeping the interest of the students can be exhausting and often requires more than one approach.

\section{FLL as a Design Coach}

This particular FIRST Lego League team mentoring activity was an assigned activity as part of a graduate course entitled "Design in Engineering Education and Practice". Although the authors participating in and evaluating the mentoring of these particular FLL teams included PhD students and engineering professors, mentoring a FLL team as an undergraduate may prove to be equally as rewarding for undergraduate engineering students. For those aspiring to be successful 
engineers, FLL mentoring provides teamwork and leadership experience. Based on the experiences of the authors, FLL mentoring will also benefit aspiring engineering academics as it provides a relevant and realistic experience for teaching design.

\section{Conclusions}

Using college graduate and undergraduate engineering students to mentor elementary and middle school FLL teams as a class assignment to teach teamwork management and organizational problem solving is an excellent strategy. It not only assists the thousands of FLL teams in search of mentors, but it also gives engineering students the opportunities to mentor actual design teams working on significant technical challenges. It also gives these mentors the opportunity to contribute to their communities by giving back some of the gift of learning that they have acquired. It is also a lot of fun and creates an environment of role models and bonding between generations of future engineers.

\section{Bibliography}

1. Self BP, Wood JJ, Hansen D. Teaching Undergraduate Kinetics Using LEGO® Mindstorms Race Car Competition. Proceedings of the 2004 American Society for Engineering Education Annual Conference and Exhibition, 2004.

2. Goff R, Vernon M. Using LEGO RCX Bricks as the Platform for Interdisciplinary Design Projects. Proceedings of the 2001 American Society for Engineering Education Annual Conference and Exposition, 2001.

3. Lau P, McNamara S, Rogers C, Portsmore M. LEGO Robotics in Engineering. Proceedings of the 2001 American Society for Engineering Education Annual Conference and Exposition, 2001.

4. Ringwood JV, Monaghan K, Maloco J. Teaching Engineering Design through LEGO Mindstorms. European Journal of Engineering Education, Vol. 30, No. 1, March 2005, 91-104.

5. Wakeman-Linn J, Perry A. A Proposal to Incorporate LEGO Mindstorms into an Introduction to Engineering Course. Proceedings of the 2002 ASEE/SEFI/TUB Colloquium, 2002.

6. Weinberg JB, Engel GL, Gu K, Karacal CS, Smith SR, White WW, Yu X. A Multi-Disciplinary Model for Using Robotics in Engineering Education. Proceedings of the 2001 American Society for Engineering Education Annual Conference and Exposition, 2001.

7. FIRST LEGO League website. [Online] Available: http://www.firstlegoleague.org/

8. Howell WL, McCaffrey EJ, Murphy RR. University Mentoring for FIRST Lego League. Proceedings of the $33^{\text {rd }}$ ASEE/IEEE Frontiers in Education Conference, November 5-8, Boulder, CO, 2003.

9. Opplinger D. Using FIRST Lego League to Enhance Engineering Education and to Increase the Pool of Future Engineering Students. Proceedings of the $32^{\text {nd }}$ ASEE/IEEE Frontiers in Education Conference, November 6-9, Boston, MA, 2002.

10. FIRST website. [Online] Available: http://www.usfirst.org/

11. LEGO website. [Online] Available: http://www.lego.com/ 